Portland State University

PDXScholar

3-14-1997

\title{
The Effects of Position Power and Personal Power on the Incidence of Sexual Harassment in the Workplace
}

Eva Marie LaBonte

Portland State University

Follow this and additional works at: https://pdxscholar.library.pdx.edu/open_access_etds

Part of the Psychology Commons

Let us know how access to this document benefits you.

\section{Recommended Citation}

LaBonte, Eva Marie, "The Effects of Position Power and Personal Power on the Incidence of Sexual Harassment in the Workplace" (1997). Dissertations and Theses. Paper 5326.

https://doi.org/10.15760/etd.7199

This Thesis is brought to you for free and open access. It has been accepted for inclusion in Dissertations and Theses by an authorized administrator of PDXScholar. Please contact us if we can make this document more accessible: pdxscholar@pdx.edu. 
The abstract and thesis of Eva Marie LaBonte for the Master of Science in Psychology were presented March 14, 1997, and accepted by the thesis committee and the department.

COMMITTEE APPROVALS:
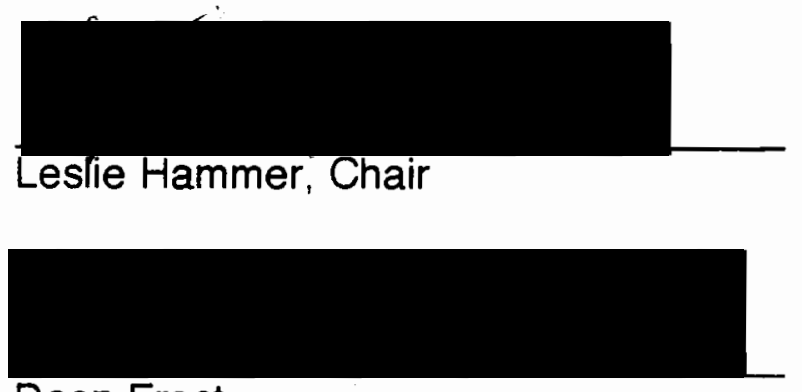

Dean Frost
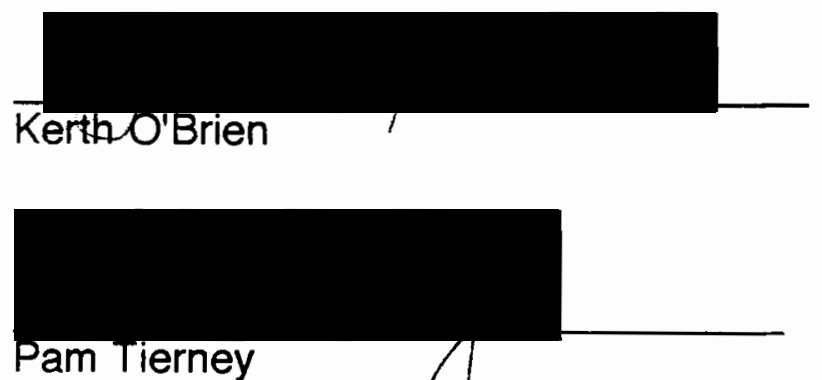

Representative of the Qffice of Graduate Studies

DEPARTMENT APPROVAL:

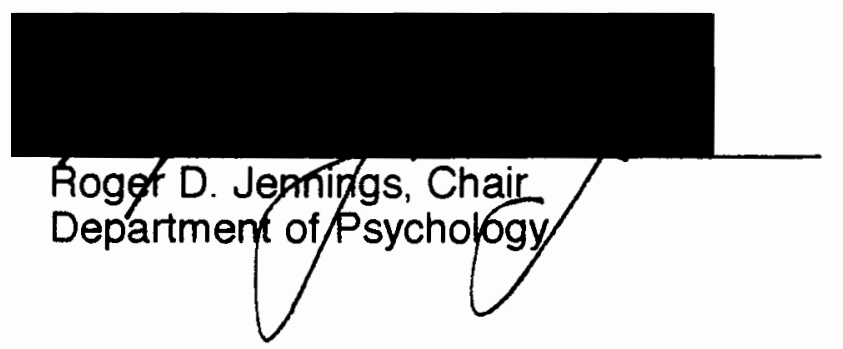

ACCEPTED FOR PORTLAND STATE UNIVERSITY BY THE LIBRARY

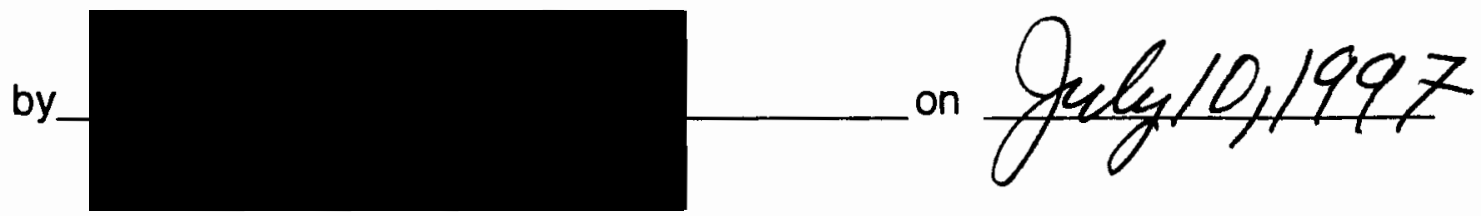




\begin{abstract}
An abstract of the thesis of Eva Marie LaBonte for the Master of Science in Psychology presented March 14, 1997.
\end{abstract}

Title: The Effects of Position Power and Personal Power on the Incidence of Sexual Harassment in the Workplace.

Sexual harassment is an important issue in today's workplace. Employees who have been sexually harassed may experience stress and a hostile, unpleasant work environment. Researchers have suggested that a person's level of power may affect the occurrence of sexual harassment.

The purpose of the present study was to partially test a theoretical model relating power and sexual harassment in order to determine if there is a connection between a victim's level of position and personal power and the incidence of sexual harassment in the workplace. The study attempted to answer the following questions: 1) Do men hold more power than women? 2) Do those with low position and personal power experience more sexual harassment than people with high position and personal power? 3) Are individuals with low position and personal power more likely to witness sexual harassment of another employee than those with high position and personal power? 4) Do women experience more sexual harassment than men?

A questionnaire was distributed to public sector employees and 118 returned the survey for a $39 \%$ return rate. Respondents were asked to (1) rate their own levels of position power and personal power, (2) provide their actual job level 
in the organization, (3) answer whether or not they had experienced any of five different levels of sexual harassment, and (4) provide standard demographic information.

Using a MANOVA, it was found that men held significantly more power than women, but follow-up ANOVAs showed that men held more power only through actual job level, and not through self-reported levels of power. Hierarchical multiple regression revealed that individuals with low position and personal power experienced a significantly higher incidence of gender harassment (the least severe form of harassment) than people with high power levels. Hierarchical multiple regression analysis also showed no difference in the level of position and personal power of respondents and incidence of directly observing sexual harassment. Regression analysis suggested that women experienced significantly more gender harassment and seductive behavior, the two least severe forms of harassment, than men. These results partially supported a previously formulated model of power and sexual harassment. 
THE EFFECTS OF POSITION POWER AND PERSONAL POWER ON THE INCIDENCE OF SEXUAL HARASSMENT IN THE WORKPLACE

$$
\text { by }
$$

EVA MARIE LABONTE

A thesis submitted in partial fulfillment of the requirements for the degree of

\author{
MASTER OF SCIENCE \\ in \\ PSYCHOLOGY
}

Portland State University

1997 


\section{TABLE OF CONTENTS}

page

List of Tables . . . . . . . . . . . . . . . . . . . .

List of Figures. . . . . . . .

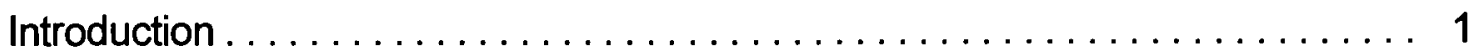

Sexual Harassment ........................... 1

The Cleveland and Kerst Model of Sexual Harassment . . . . . . . . . 4

Witnessing Sexual Harassment ...................... 5

Power Issues in the Workplace $\ldots \ldots \ldots \ldots \ldots \ldots \ldots \ldots \ldots$

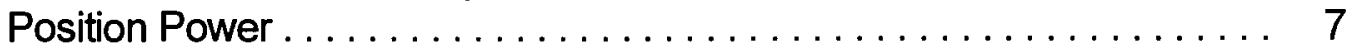

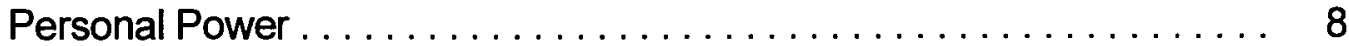

Hypotheses $\ldots \ldots \ldots \ldots \ldots \ldots \ldots \ldots \ldots \ldots \ldots \ldots \ldots \ldots, 9$

Method ....................................... 10

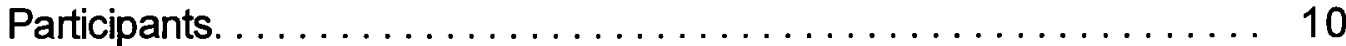

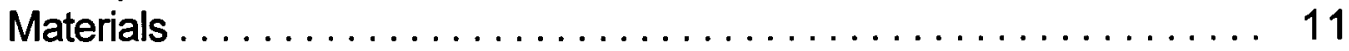

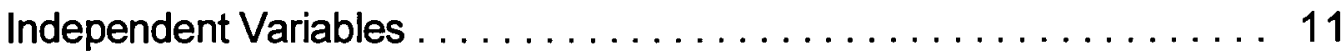

Dependent Variables .............................. 12

Procedure ................................... 13

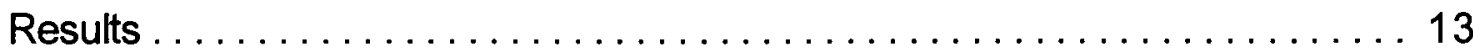

Descriptive Statistics .......................... 13

Tests of Hypotheses . . . . . . . . . . . . . . . . . . . . . . 15

Discussion .................................... 18

Limitations ............................. 27

Future Research and Implications of the Research Findings . . . . . 29

References .................................... 40

Appendix ........................................ 45 


\section{LIST OF TABLES}

Table page

1 Incidence of Sexual Harassment Variables ............. 31

2 Pearson Correlation Coefficients for Study Variables . . . . . . . 32

3 Responses to the survey question "Sexual Harassment occurs in my workplace." . . . . . . . . . . . . . . . . 33

$4 \quad$ Responses to the survey question "Sexual Harassment is NOT a problem in my workplace." . . . . . . ........... 34

5 Results of the MANOVA Analysis of Gender and Levels of Power.

6 Results of Multiple Hierarchical Regression Analysis of Power and Incidence of Sexual Harassment . . . . . . . . . . 36

7 Results of Multiple Hierarchical Regression Analysis of Power and Incidence of Witnessing Sexual Harassment ............ 37

6 Results of Single Regression Analysis of Gender and Sexual Harassment ......................... 38 


\section{LIST OF FIGURES}

Figure

page

1 The Cleveland and Kerst model of power and sexual harassment 
The Effects of Position Power and Personal Power on the Incidence of Sexual Harassment in the Workplace

Although it is not a new issue in organizations, the last decade has seen an increase in interest and research on the topic of sexual harassment in the workplace. Due to the complex nature of sexual harassment, there is no clear definition of what constitutes harassing behavior. In fact, the lack of a generic definition may cause problems in identifying, and thus reporting, sexual harassment in the workplace. If each person has a distinct view of sexual harassment, it is likely that there will be a conflict in the way different individuals perceive incidents of harassing behavior. This study examined the differences in power between victims of sexual harassment and those who are not victimized by harassing behavior in the workplace. The purpose of this study was to partially test a model proposed by Cleveland and Kerst (1993) which suggests that work conditions, combined with both position and personal power, can help to predict the incidence of sexual harassment in the workplace.

Sexual Harassment

According to Chapin and Norton-Bradley (1993), sexual harassment can be defined as unwanted or unwelcome verbal or physical conduct with sexual overtones. This unweicome conduct must meet at least ONE of the following requirements:

1. Submission to the conduct is made, explicitly or implicitly, a condition of employment. 
2. Submission to, or rejection of, such behavior is used as the basis for employment decisions for the victim.

3. Such conduct has the purpose or effect of unreasonably interfering with an individual's work performance or creates an intimidating, hostile or offensive work environment.

It is important to note that the harassing conduct does not have to be intentionally offensive to be classified as sexual harassment. As long as the behavior resulted in creating a hostile or uncomfortable workplace for the victim, it is sexual harassment. This definition is also the legal definition of sexual harassment (Chapin \& Norton-Bradley, 1993).

When speaking of sexual harassment, most people envision males harassing females. In fact, it has been established that most incidents of sexual harassment are men harassing women (Fitzgerald, 1988; Hotelling, 1991), although the opposite does occur (Stockdale, 1996). Several different theories have attempted to explain the causes for sexual harassment in the workplace. Research has attributed harassing behavior to the misinterpretation of communication between men and women (Stockdale, 1993). The misinterpretation theory of sexual harassment, which only addresses men harassing women, is based on the assumption that males often distort a female's friendliness as flirtation. This implies that the men think their harassing behavior is desired. However, recent research has not supported this scenario (Stockdale, 1996).

Some social psychologists suggest that sexual harassment is due to a combination of situation and personality factors (Pryor, 1987; Pryor, LaVite, 
\& Stoller, 1993). The studies proposed that the personal characteristics of the offender, together with social acceptance of sexual harassment, are the driving forces behind harassing behavior. In fact, these theories were supported with empirical tests (Pryor, 1987). Men with a High Likelihood to Sexually Harass (LSH) harassed women more when the male experimenter modeled this behavior; men with a high LSH did not sexually harass women significantly more than other men when the experimenter did not model harassing behavior. This would suggest that men with negative attitudes toward women or those with traditional sex role stereotypes are more likely to sexually harass in an environment where harassment is acceptable.

In addition, certain sociologists view sexual harassment as simply the most visible part of many different workplace disputes (Lach \& GwartneyGibbs, 1993). According to these researchers, various factors in the workplace degrade women, including gender-stereotyped jobs and hiring women based on meeting affirmative action quotas, as well as sexual harassment. This model suggests that women should look at several problematic issues that are occurring in the workplace that are all causing employed women to be second class citizens.

Miscommunication between genders, social norms, accepting sexuality on the job, and the degradation of females all have one common theme: The use of power. Cleveland and Kerst (1993) have developed a model which examines harassing behavior as a function of work conditions and the different levels of power held by men and women. The current paper proposes empirical research to partially test the Cleveland and Kerst model 
on the effects of power, and the perceptions of this power, on sexual harassment in the workplace.

The Cleveland and Kerst Model of Sexual Harassment

Cleveland and Kerst (1993) have developed a model which proposes that sexual harassment occurs due to a combination of societal and organizational factors (work conditions) and both the harasser's and the victim's level of personal and position power (see Figure 1). According to Cleveland and Kerst, sexual harassment often occurs when one individual holds more personal and/or position power than another, and the organizational environment is conducive to the abuse of this power imbalance. In this model, sexual harassment does not occur because the perpetrator desires a sexual relationship, but because the harassing behavior is an acceptable method of exerting power and influence in the workplace.

The working definitions of the key terms utilized in this model are outlined below. This study examined only a piece of the Cleveland and Kerst model: The effects of a victim's personal and position power on the incidence of sexual harassment in the workplace were empirically tested. Societal factors and organizational factors, which comprise work conditions, along with the perpetrator's level of power, will not be included in this research. However, all areas of the model are discussed below in order to provide a complete understanding of Cleveland and Kerst's theory.

According to this model, work conditions consist of both societal and organizational factors. Societal factors include some of Western society's social norms. Individuals often learn through observation, example and 
experience that men typically hold greater power than women, and males are socialized and expected to be goal-oriented and exercise greater influence than women (Mainiero, 1986). On the other hand, it is often assumed that women should hold less power than men and are socialized to take on a more passive role at work (Eagly \& Mladine, 1989). The belief that traditionally men are emotionally and physically stronger than their female counterparts allows males to appear to be more competent to handle stress and the requirements of high status, high paying jobs. This, in turn, enables men to acquire even more position and personal power than women.

Organizational factors are quite often an extension of societal factors in the workplace. Often women occupy the lower status jobs in organizations, and they are assumed to be better able to handle the requirements of the lower level positions such as clerical or sales jobs (Ragins \& Sundstrom, 1989). Although this stereotype appears slowly to be changing, most work environments are far from viewing men and women as equally capable workers. In addition, organizational factors are affected by the individual attitudes of each employee. As every person enters the workplace with his or her own standards, biases and value systems, the organizational culture is largely affected by the personal culture of its employees (Cleveland \& Kerst, 1993).

Witnessing Sexual Harassment

One area of sexual harassment that has received very little attention in previous studies is witnessing harassment - actually observing another 
person being sexually harassed. This uncharted area was examined in the present study in an attempt to establish empirical data related to this issue.

Since a low percentage of victims of sexual harassment report its occurrence (Gruber, 1989), it is also possible that a small number of people would admit to witnessing harassment. However, it is possible that, when asked, a significant number of people would report directly observing harassing behavior. This part of the current study has the potential to provide more insight on the prevalence of sexual harassment in the organization, as well as information on the correlation between the number of people being harassed and the number of people reporting observing it happen.

\section{Power Issues in the Workplace}

Society has many definitions of the term 'power'; generally, it is used as a way of indicating that one person has more strength or influence than another person. This study referred to the word 'power' as a person's potential influence over the attitudes and behaviors of one or more designated individuals (Yukl, 1989). This definition was used because it acknowledges that power has the potential to change an individual's demeanor as well as his/her behavior.

The current study examined the role of a victim's level of position power and personal power in contributing to the incidence of, and attitudes toward, sexual harassment. Position power includes formal authority, as well as control over resources, rewards, punishment and information, while personal power consists of expertise, loyalty and friendship (Yukl, 1989). 
An individual's use of power is manifested in a variety of ways, depending on the personality of the individual, the situation, and the type of power utilized. Prior research has suggested that men are associated with the strong tactics of reward, coercion, and expert power, while women have been found to utilize more covert strategies, such as deceit, helplessness and passivity (Wiley \& Eskilson, 1982). If men and women were to use these stereotypical forms of communication and influence, both the position and personal power in the workplace would be held by the males.

Men often hold more high-status positions than women; this provides males with a basis to exercise position power over others. In addition, personal power, in the form of socialization, charisma, loyalty and good group dynamics, is an important part of influencing others in the workplace (Yukl, 1989). Research has found that women are often either weakly linked or excluded from this informal power network, which may include alliances with mentors, superiors, and co-workers (Pfeffer, 1981). If women do not have access to the power network, they may be perceived as possessing less personal power, and thus holding less influence or significance in the organization.

\section{Position Power}

Position power is comprised of several components. The first is formal authority, also known as legitimate power (Raven, 1983). This type of power is possessed by an individual due to his or her position in the organization. Formal authority allows a person to influence the behavior of others with less authority (Yukl, 1989). A second aspect of position power is control over 
resources, which is closely related to formal authority; an individual who is higher in the organizational hierarchy will posses more control over the allocation of resources, such as funding and equipment (Pfeffer, 1992).

Another aspect of position power involves control over rewards and punishment, which is often associated with promotion or demotion in career advancement and compensation (Yukl, 1989). For instance, a person who makes the decision to promote or fire employees will most likely have considerable power and influence over other workers. Finally, a fourth component of position power is control over information, which involves the access to, and distribution of, vital facts to the organization (Pfeffer, 1992).

\section{Personal Power}

Personal power relates to the attributes of the interpersonal relationship between two people (Yukl, 1989), and it can play a critical role in influencing other people. Often, a strong leader will not only possess access to power through his or her position, but will also have the ability to associate with others effectively.

Expertise is a main source of personal power in organizations, and it consists of the ability to solve problems and perform important tasks (Yukl, 1989). Often referred to as expert power, this form of control is frequently the key to personal power because it also commands respect from other employees. Friendship and loyalty, often termed referent power, is comprised of a genuine affection and willingness to perform special tasks or favors for another (Yukl, 1989). Often, it takes time to establish referent power, and it is usually influenced by expertise and charisma (Pfeffer, 1989). 
Personal power is a more subtle form of persuasion than position power, but both types of power have the potential to strongly influence an individual's attitudes and/or behavior.

In summary, an individual's position and personal influence have the potential to create a large source of power in organizations. Power, then, is created by the variation in the position and personal influence one individual has over another, which can lead to the capacity of one person to overcome resistance in achieving a desired objective or result (Kerst \& Cleveland presentation, 1993) For a comprehensive overview of gender and power in organizations, see Fitzgerald and Shullman (1993), and Ragins and Sundstrom (1989).

\section{Hypotheses}

On the basis of previous research, Cleveland and Kerst (1993) have developed a conceptual model to explain sexual harassment as a function of power in the workplace. However, it is necessary to test this model empirically in order to determine its validity and usefulness. As previously stated, the issue of sexual harassment is complicated, and there are most likely a number of factors that influence its occurrence. However, the current study focused on the differences in power between persons who reported being victimized by sexual harassment and persons who did not report being victims of harassing behavior. This research will center on a department of the county government system that utilizes a formal, obvious power hierarchy (similar to the military). There is little prior published research testing 
Cleveland and Kerst's model; thus, this study may offer new insights into the role of power in sexual harassment.

The following hypotheses were posed:

Hypothesis 1: Men will hold more position and personal power than women.

Hypothesis 2: Individuals with low personal and position power will report a significantly higher rate of experiencing sexual harassment than individuals with high personal and position power, over and above the subjects' demographic differences.

Hypothesis 3: Individuals with low position and personal power will report a significantly higher rate of directly observing sexual harassment of other employees than individual with high position and personal power, over and above the subjects' demographic differences.

Hypothesis 4: Women will report a significantly higher rate of experiencing sexual harassment than men.

Method

\section{Participants}

The participants of this study included all people employed at a county government department. This subject pool was selected because this department had a formal organizational hierarchy with clear distinctions between the different levels of position power. The total number of available subjects was 302 . 
Power and Harassment

\section{Materials}

Employees were asked to fill out a questionnaire which included information on demographics, including age, gender, ethnicity, and length of employment. Additionally, personal power, position power, and incidence of sexual harassment were assessed.

\section{Independent Variables}

Position and personal power. Frost and Stahelski's (1988) 23-item questionnaire that measures an individual's use of five bases of social power in organizations, based on French and Raven's theoretical model (French \& Raven, 1959), was used to assess position and personal power in the current study (see Appendix, questions 1-29). The questions were presented in random order. The five bases include: Legitimate power, Coercive power, Reward power, Expert power and Referent power. This study divided the five bases into either position or personal power consistent with Frost and Stahelski (1988). Position power included Legitimate, Coercive and Reward power, while personal power consisted of Expert and Referent power. The Power section of the questionnaire was scored on a five point, Likert-type scale, ranging from $1=$ Never, to $5=$ Almost Always. For Position Power, the current study showed an internal consistency reliability estimate of $\propto$ $=.90$, and the internal consistency reliability estimate for Position Power was $\alpha=.81$.

The current study also asked the subjects to provide information related to their current position in the organization. Participants categorized their job as either 1) Non-supervisory (low status); 2) Supervisor (medium 
status); or 3) Supervises others who are also supervisors (high status). This information was used as the Reported Job Level variable.

Dependent Variables

Incidence of sexual harassment. In order to determine incidence of sexually harassing behavior, the Sexual Experiences Questionnaire (SEQ) (Fitzgerald \& Shullman, 1993) was used. This questionnaire identifies five levels of sexual harassment without actually labeling the behavior as harassment (See Appendix, questions 30-61). The current study presented the questions in random order. The SEQ allows for more accurate reporting of harassing behavior, as previous studies have shown that although harassing behavior occurs, only $3-5 \%$ of subjects identified that behavior as harassment, mainly because respondents did not believe the behavior was serious enough to be termed harassment (Brooks \& Perot, 1991). Thus, the SEQ is a useful tool in attempting to uncover sexual harassment in an organization where actual reporting of harassing behavior may be very low. The SEQ was scored as either 'Yes' (the experience in question did occur) or 'No' (the experience in question did not occur). This questionnaire has demonstrated acceptable internal consistency reliability $(\alpha=86)$ in previous studies. (Fitzgerald et al., 1988).

The five levels of harassment identified by the SEQ are, from least to most serious, gender harassment, seductive behavior, sexual bribery, sexual coercion, and sexual assault (see Appendix, questions 30-61, for examples of each of the levels of harassment). Additionally, the subjects were asked to mark a separate column if they were a direct witness to a co-worker 
Power and Harassment

encountering any of the behaviors. Witnessing sexual harassment is not part of the original SEQ; this section was added for this study. This additional section was anticipated to shed light on witnessing harassing behavior. Furthermore, this information was used as a second measure of the prevalence of harassing behavior in the organization, as well as providing information on the organization's work conditions.

\section{Procedure}

The survey was delivered to each subject through the organization's mail system. A cover letter emphasized that the questionnaire would be utilized for a master's degree thesis, and that all information would be anonymous (see Appendix). It also stated that the County Administrator had agreed to allow employees to complete the survey on work time, or the employee could take it home and fill it out. In addition to the survey a confidential return envelope was included, along with specific instructions as to the locations of the several secure drop boxes which were placed around the department. The drop boxes were used in order to make it easier to return the surveys, as well as to further secure the subjects' anonymity. The ease of returning the questionnaire was anticipated to increase the response rate of the subjects. A two week window was available for the subjects to complete and return the questionnaire.

\section{Results}

\section{Descriptive Statistics}

Of the 302 surveys distributed, a total of $118(39.1 \%)$ were returned. Respondents included $67(56.8 \%)$ males, 47 (39.8\%) females, and 4 persons 
(3.4\%) not indicating gender. The respondents ranged in age from 18 to 63 , with a mean age of 39 years. The mean number of years worked at this organization was 8.9 years, with a range of less than 1 to 27 years. Ninetyfive percent of the survey respondents were Caucasian.

Power. Non-supervisory employees accounted for $72.4 \%$ of those responding (76 people), $19.0 \%$ were supervisors (20 people), and $8.6 \%$ were top-level supervisors who managed employees who are also supervisors ( 9 people). Of the non-supervisory respondents, $51 \%$ were male, $60 \%$ of the supervisory respondents were male, and $89 \%$ of the top-level supervisors were male. The mean for Personal Power was 3.23 , with a standard deviation of .60. The mean for Position Power was 2.53, with a standard deviation of 62 .

Incidence of sexual harassment. In examining the overall incidence of sexual harassment, $72 \%$ of the respondents $(n=85)$ reported being sexually harassed in some way. Of the $72 \%$ who were harassed, $68 \%$ reported experiencing Gender Harassment (Level 1); $45 \%$ were the victims of Seductive Behavior (Level 2); $5 \%$ reported experiencing Sexual Bribery (Level 3); $4.5 \%$ encountered Sexual Coercion (Level 4); and 18.6\% experienced Sexual Assault (Level 5) (see Table 1). Thus, there was a distinguishable difference between the number of respondents reporting sexual harassment in Levels 1 and 2 as compared to Levels 3,4 and 5 . See Table 2 for the intercorrelations of the study variables.

Due to a sharp decrease in reported incidence of sexual harassment between Level 2 (seductive behavior) and Level 3 (sexual bribery) 
Harassment (see Table 1), the analyses used only Level 1 and Level 2 Harassment as the Reported Incidence of Harassment variables.

When asked if sexual harassment occurs in their workplace, $13 \%$ responded Never, $48 \%$ responded Seldom, $21 \%$ responded Occasionally, $2 \%$ responded Often, $8 \%$ responded Almost Always, and $8 \%$ did not respond. Examining the responses by gender, men reported $12 \%$ Never, $67 \%$ Seldom, $17 \%$ Occasionally, $3 \%$ Often and $2 \%$ Almost Always. Women answered $15 \%$ Never, 35\% Seldom, $28 \%$ Occasionally, $20 \%$ Often and $2 \%$ Almost Always (see Table 3).

Respondents were asked if sexual harassment was a problem in their workplace. Thirty-seven percent agreed it was a problem, while $51 \%$ reported sexual harassment was not a problem. Sixteen percent either had no opinion or did not respond to the question. Examining the responses by gender, $68 \%$ of the men believed sexual harassment was not a problem, while $26 \%$ responded that it was a problem. Of the women respondents, $40 \%$ answered that harassment was not a problem, and $44 \%$ thought it was a problem. (see Table 4).

\section{Tests Of Hypotheses}

Gender and levels of power. A one way multiple analysis of variance (MANOVA) was conducted to test Hypothesis 1 to determine if men held significantly more Personal Power and Position Power than did women in the workplace. Gender was entered as the categorical independent variable while the continuous dependent variables included Reported Job Level (coded on a 1 through 3 scale, where 1 equaled non-supervisory, 2 equaled 
supervisory and 3 equaled top level supervisors), overall Personal Power, and overall Position Power.

Results of the one way MANOVA demonstrated partial support for the first hypothesis; men possessed significantly more power than women $[E(3,105)=3.22 ; p \leq .03]$. Three separate follow-up ANOVA's were run to examine the specific effects of Reported Job Level, Position Power and Personal Power. These ANOVAs showed that men held significantly more formal authority through Reported Job Level $[E(1,103)=4.34 ; p \leq .04]$, but not through either Personal or Position Power (see Table 5). Therefore, Hypothesis 1 was partially supported.

Power and the incidence of sexual harassment. Hierarchical multiple regression analyses were conducted to examine the amount of variance in sexual harassment that was accounted for by perceived Personal and Position Power over and above demographic variables. Due to the sharp decrease in reported incidence of sexual harassment between Level 2 and Level 3 Harassment (see Table 2), this analysis used only Level 1 and Level 2 Harassment as the Reported Incidence of Harassment variables. Thus, Gender Harassment (Level 1) and Seductive Behavior (Level 2) were compared with the Power variables. After controlling for the demographic variables (gender and age) and Reported Job Level, the Personal and Position Power variables were entered into the regression equations.

Results of the hierarchical multiple regression analysis for Power and the Incidence of Gender Harassment (Level 1) showed support for Hypothesis 2; Personal and Position Power accounted for a significant 
amount of variance in the incidence of Gender Harassment, above and beyond the variance attributed to demographics $(\Delta \underline{R} \underline{2}=.06, \underline{F}(5,91)=3.11$; $\mathrm{P} \leq$.05). In a second analysis, hierarchical multiple regression analysis for Power and the incidence of Seductive Behavior (Level 2 ) demonstrated that Personal and Position Power were not significant predictors of higher incidence of Seductive Behavior (see Table 6). Therefore, Hypothesis 2 was partially supported.

Power and witnessing sexual harassment. Hierarchical multiple regression analyses were conducted to examine the amount of variance accounted for in directly witnessing sexual harassment by perceived Personal and Position Power, over and above demographic differences. As in previous analyses, Level 1 (Gender Harassment) and Level 2 (Seductive Behavior) were used as the Reported Incidence of Sexual Harassment variables (see Table 1). Again, Level 1 Harassment and Level 2 Harassment were compared separately with the Power variables. After controlling for the demographic variables (gender and age) and Reported Job Level, the Personal and Position Power variables were entered into the regression equations. The outcome of the hierarchical multiple regression analyses for Power and Directly Witnessing Gender Harassment (Level 1), as well as the analysis for Power and Directly Witnessing Seductive Behavior (Level 2) did not show support for Hypothesis 3. Reported level of Personal and Position Power did not account for a significant variance in directly witnessing sexual harassment (see Table 7). Therefore, Hypothesis 3 was not supported. 
Power and Harassment

Gender and the incidence of sexual harassment. Simple regression analyses were conducted to determine the amount of variance accounted for in the incidence of sexual harassment by gender. As in the analyses for Hypothesis 2 and 3, Level 1 and Level 2 Harassment were used as the Reported Incidence of Sexual Harassment variables. Thus, Gender Harassment (Level 1) and Seductive Behavior (Level 2) were compared separately with the gender variable.

Results of the regression analysis for the incidence of Gender Harassment (Level 1) and gender demonstrated support for Hypothesis 4; women reported a significantly higher rate of experiencing Level 1 sexual harassment than men $(\Delta \underline{R} \underline{2}=.08, \underline{F}(1,112)=10.00 ; p \leq .01)$. In addition, multiple regression analysis for incidence of Seductive Behavior (Level 2) and gender also supported Hypothesis 4; women reported a significantly higher rate of experiencing seductive behavior than did men $(\Delta \underline{R} \underline{\underline{2}}=.08, \underline{F}(1,112)=9.38$; $\mathrm{p} \leq$.01) (see Table 8). Therefore, Hypothesis 4 was supported.

Discussion

The present study, based in part on Cleveland and Kerst's multi-level analysis of power and sexual harassment (1993), examined the relationship between an employee's level of personal and position power and the incidence of sexual harassment in the workplace. Overall, almost threefourths of the respondents reported they had been the recipient of some form of sexually harassing behaviors in the workplace. However, when asked directly about the incidence of sexual harassment, over $75 \%$ of men said that 
sexual harassment either seldom or never occurs. On the other hand, almost half of all women said sexual harassment occurs either occasionally or often. Thus, there was a discrepancy between how men and women viewed sexual harassment, as well as how the different genders rated its occurrence.

Most individuals do not want to believe that they are victims, or that bad things can happen to innocent people. This is known as the "Just World Hypothesis" (Koss, 1990). Often, men and women want to believe that life is fair, and that all people get what they deserve. Admitting to being a victim of sexual harassment shatters an individual's belief in a just world. Thus, in order to maintain belief in a just world, targets of sexual harassment may simply deny its existence.

The finding of a discrepancy between the number of people reporting experiencing harassing behaviors and the number who believe sexual harassment occurs in their workplace also suggests that not all people have the same perceptions of what constitutes sexual harassment. The experience of sexual harassment and the perception of sexual harassment can be very different (Stockdale, 1996). The Western culture that we live and work in has accepted sexual harassment for many years, and although the population today is more aware and educated about sexual harassment, it certainly still exists. According to the socio-cultural model by Tangri, Burt and Johnson (1982), sexual harassment is a product of the norms, stereotypes, values, and general expectations that prevail in Western 
Power and Harassment

society, which generally means that men dominate over women. Domination today has a more acceptable name: Power.

In the current study, it was hypothesized that men would hold more personal power and position power than would women in the workplace, where power was measured by self-reports of personal power and position power, as well as reported job level (which was an objective measure of power). The results showed that men hold more power, through formal authority, than women, and specifically men possessed significantly more power than women only through reported job level. The finding that men hold more power than women through job level corresponds to the idea that the hierarchy of an organization is a critical antecedent to sexual harassment (Hulin, Fitzgerald \& Drasgow, 1996). Yukl (1989) reported that men often hold more high-status positions than women, which allows males more access to position power. On the other hand, women have been found to be weakly connected to the power network (Pfeiffer, 1981.)

Those who have access to the high-status positions and power networks of role, responsibility, and authority can abuse this power and use their position to sexually harass others (Tangri et al, 1982). Additionally, organizational climate is related to the acceptance of cultural norms, where men typically dominate and possess more power than women (Tangri et al., 1982). In a business where both organizational and cultural norms place men in a position of power, an individual's personal power may not be as important as position power. 
Power and Harassment

The fact that self-reported personal and position power were not significantly linked to gender does not support the work of Yukl (1988), who found that personal power, in the form of socialization, charisma and loyalty, is a significant part of influencing others in the workplace. Additionally, these findings do not agree with the feminist approach, which views the cause of sexual harassment not as a job level issue, but as a combination of social and psychological power (Barak, Pitterman \& Yitzhaki, 1995). In general, previous research devoted to power issues, gender, and sexual harassment is sparse and inconclusive (Stockdale, 1996).

The current study also hypothesized that individuals with higher personal and position power would report a significantly lower rate of experiencing sexual harassment, and that power would account for a significant amount of variance in sexual harassment over and above demographic differences. Due to a low incidence of Levels 3, 4 and 5 harassment (sexual bribery, sexual coercion and sexual assault, respectively) only Levels 1 and 2 (gender harassment and seductive behavior) were examined in this study.

It was found that those with higher levels of personal and position power did experience significantly less gender harassment (Level 1 harassment) but seductive behavior was not related to power in this case. This finding partially supports the Cleveland and Kerst model on which the study was based (1993), which concludes that an individual's personal and position power are related to the incidence of harassing behavior. 
Power and Harassment

These results suggest that an individual's power can act as a deterrent to becoming a victim of the least severe, yet most common, form of sexual harassment. For example, a person who possesses high personal and position power may be less likely to encounter sexually laced stories or suggestive comments about his or her appearance than does an individual who has lower personal and position power. The findings of past research on power and sexual harassment, including Kipnis, Cleveland and McNamera (1996), as well as Koss and Dinero (1988), examined the perpetrator's high level of power which influences the occurrence of sexual harassment. However, the current study looked at the level of power of sexual harassment victim. More research on the power levels of victims is needed in order to substantiate the ability of a potential victim's power to act as a deterrent to sexual harassment.

Research relating power directly to sexual harassment is sparse (Stockdale, 1996), but there has been speculation about this connection for some time. In fact, sexual harassment has been labeled an "unwelcome imposition of sexual requirements in the context of a relationship with unequal power" (Stockdale, 1996). Power, in the form of the need to exercise control over others, in combination with hostility toward females, has been found in individuals likely to commit acts of sexual violence (Cleveland \& McNamera, 1996; Koss \& Dinero, 1988). Kipnis (1990) found that those with power over others viewed individuals with less power as weak and lazy. Additionally, the fact that the current study found that those with less power experienced more harassing behavior can be linked to culture, as well as the 
Power and Harassment

culture of an organization (Stockdale, 1996), which often allows those in a position of power to use that power to unfairly influence others. According to Thacker (1996), the person with high position power in an organization is armed with the ability to affect job-related outcomes, such as providing critical information, performance evaluations, and salary increases. In the current study, and in society in general, men hold a significantly higher number of high status positions which leads to organizational power. An organization that accepts the long tradition of awarding most of the high power positions to males may be more likely to perpetuate the existence of sexual harassment in the workplace.

It is interesting to note the dramatic difference between the percentage of respondents reporting the lower levels of sexual harassment (gender harassment and seductive behavior) as compared to the more severe, violent acts of harassment (sexual bribery, sexual coercion and sexual assault). One explanation for these results relates to how individuals view sexual harassment. Powell (1990) found that people are more likely to believe that a behavior is sexual harassment as the harm to the victim increases. Perhaps gender harassment and seductive behavior continue to exist, even when people have been educated that sexual harassment is wrong, because these behaviors are still not seen as physically harmful to the victim; the psychological damage that sexual harassment can cause is often overlooked. Conversely, it is not difficult to recognize that sexual coercion and assault are damaging to the victim. It is important to educate people that all forms of sexual harassment are potentially harmful, causing 
higher absenteeism, lower work productivity, lower job satisfaction, negative outcomes related to physical and mental health, and can even force individuals to leave their job (Gutek \& Koss, 1993; Thacker, 1996).

The third hypothesis examined the relationship between a person's level of personal and position power in the workplace and the incidence of directly witnessing sexual harassment (that is, observing harassing behavior that is not directed at the person observing it). It was hypothesized that individuals with lower levels of power would report a significantly higher rate of directly observing sexual harassment, and that power would account for a significant amount of variance in directly observing sexual harassment over and above demographic differences. Once again, only Levels 1 and 2 (gender harassment and seductive behavior) were utilized in examining this hypothesis. The results did not support this hypothesis.

One explanation for this finding is that sexual harassment does not occur as often in the presence of others. Potential harassers may consider the negative reaction they might elicit from the observers, and thus not take part in harassing behavior when others are watching (Pryor, LaVite \& Stoller, 1993). Another justification for discovering no power differential in witnessing sexual harassment could be a fear of the phenomenon known as "whistle-blowing" (Dandekar, 1990; Near \& Miceli, 1987). Some individuals may believe that telling anyone their co-workers have sexually harassed others is disloyal to fellow employees, as well as to the organization. Employees who feel that an acknowledgment of having witnessed 
harassment is whistle-blowing will either simply not reveal the information, or they may believe that it is not important enough to mention.

Although this investigator made every attempt to assure the respondents of the survey's anonymity, there may have been some who still harbored some doubt about confidentiality. If so, those people's experience of responding would relate to the moral decision-making perspective. According to Bowes-Sperry and Powell (1996), an individual who has observed sexual harassment and determined that it is wrong has triggered an ethical decision-making process. To decide to admit the witnessed harassment occurred means that the individual has deemed sexual harassment morally wrong, since responses that are not kept confidential could potentially involve some type of harm to the person who gives the information. Thus, from an ethical standpoint a person would only risk admitting to witnessing sexual harassment if the individual felt it was morally wrong. In the current study, this would suggest that perhaps most people did not feel that gender harassment or seductive behavior is morally wrong enough to risk admitting to witnessing a co-worker participating in harassment. Alternatively, perhaps sexual harassment was simply not observed by the respondents.

Finally, it was hypothesized that women would report a significantly higher rate of experiencing sexual harassment than men. The findings in the current study supported prior research (Fitzgerald, 1988; Hotelling, 1991, Stockdale, 1996); women encountered a significantly higher rate of sexual harassment than did men. Consistent with these findings, a previous study 
Power and Harassment

also using public sector employees ( 8,000 government workers) found that $15 \%$ of males reported harassing behavior, while $42 \%$ of the female respondents were harassed (U.S. MSFB, 1988.)

Why do women encounter significantly more sexual harassment in the workplace than their male counterparts? Prior studies have shown than men are less likely than women to label an action as sexual harassment (Kenig \& Ryan, 1986; Stockdale \& Vaux, 1993). It is possible, then, that men experience sexual harassment, but may not find harassing behavior offensive. Because these men may not perceive the behavior as a problem, in their minds it may not constitute sexual harassment. Men have also been found more likely than women to believe that sexual harassment victims contribute to their own harassment by either provoking it or by not "properly" handling a normal amount of sexual attention (Bowes-Sperry \& Powell, 1996; Jensen \& Gutek, 1982). It is possible that if some men feel that sexual harassment is partially caused by the victim, then these men would also believe that they were partially responsible for any harassment they might encounter, and thus not label the behavior sexual harassment.

Research examining female targets of sexual harassment have found that women are, for the most part, non-assertive in their responses to harassment (Gruber \& Smith, 1995). In reviewing 10 studies, Gruber (1989) discovered only $10-15 \%$ of the women either responded assertively to sexual harassment or reported the behavior. Some common responses by females to sexual harassment include ignoring it or pretending not to notice (McKinney, 1990), avoiding the harasser, and making jokes about the 
Power and Harassment

harassment to defuse the hostility (Gruber \& Smith, 1995). When women did talk about being sexually harassed, it was more frequently to a friend or coworker than to a supervisor (Gruber \& Smith, 1995).

It appears, then, that men have been found to more often be the perpetrators of sexual harassment, and possess a lower awareness that sexual harassment exists and that it is a problem in today's workplace. Women, on the other hand, are cognizant of harassment and its effects, but often respond non-assertively or do not respond at all. While males need to become more aware of the existence of sexual harassment and learn how to avoid harassing others, females may want to be more assertive about telling supervisors, and the harassers themselves, that sexual harassment will not be tolerated. In general, organizations seem to have difficulty in breaking through the cultural stereotype of placing men in positions of power, which has perpetuated sexual harassment for many years. There are many issues involved in the roots of sexual harassment, and power is embroiled in almost every aspect of harassing behavior.

Limitations

One limitation of the current study is that this research only examined a small part of a much larger model, and thus no definitive conclusions can be drawn about the Cleveland and Kerst (1993) model of sexual harassment as a whole without further research. A second limitation is the small sample size; a larger number of respondents may have provided enough data to examine how power relates to all five levels of sexual harassment, as opposed to only the first two levels of harassment that were examined in the 
current study. A larger sample may also have proven to be useful in analyzing directly witnessing sexual harassment, since there was a low number of respondents in this area. A third limitation is that position power, personal power and reported job level were very closely intercorrelated. It is possible that position power and reported job level were measuring relatively the same thing, thus potentially skewing the results.

Another limit to the study is the fact that the research was conducted with public sector employees who are specially trained to be suspicious and cautious in revealing any information to an unknown source. This may have caused some of the respondents to question the confidentiality of the survey. Doubts about confidentiality could have two effects. First, it could hinder potential respondents from turning in their questionnaire at all, and thus lowering the response rate. Second, those who did turn in the survey may have not been completely honest in their responses, fearing that too many "wrong" answers might draw negative attention to their questionnaire. Additionally, there have also been recent lawsuits against the agency used in this study relating to issues of sexual harassment, which could affect the belief in the legitimacy of the survey's claim of confidentiality. Finally, this investigator discovered, through conversations with employees in the department used in this study, that this work environment was seen as strongly male-oriented and possessed a distinct power hierarchy. Therefore, the results may not be applicable to organizations with a more loose structure and gender-balanced workforce. 


\section{Future Research and Implications of the Research Findings}

In summary, the current study revealed that men held more power than women (when power was measured by reported job level), individuals with lower power had a higher incidence of gender harassment (Level 1 harassment), and women had a significantly higher rate of experiencing sexual harassment than did men. These findings support a portion of the Cleveland and Kerst (1993) model which explores the antecedents of sexual harassment as they relate to power. Future research must incorporate the entire model in order to completely examine this multi-level design. Additionally, organizations need to examine the culture of their work environment, and take steps to remove the barriers that perpetuate more men than women holding positions of power. This would include looking at the effectiveness of existing policies on responding to sexual harassment claims, and making sure victims feel comfortable in reporting harassing behavior.

It would be advantageous for researchers to attempt to duplicate the current study utilizing an organization with less rigid lines between job classifications. A larger subject pool with a more even gender distribution should also be used in follow-up studies, which would help in the generalizability of the findings. Additionally, the tools used to examine power should be less intercorrelated than those used in the current research.

Research that examines how a person's power can act as a deterrent to potential harassers would be a valuable tool in further understanding why 
Power and Harassment

people become the target of sexual harassment. More studies examining the direct relationship between victim power, perpetrator power and the occurrence of sexual harassment are necessary; there are a large number of explanations for harassing behavior that involve power, but the immediate relationship deserves additional attention. Further investigation into the relationship between power and sexual harassment is essential in order to validate this important element in understanding the origins and effects of sexual harassment in the workplace. 
Table 1

Incidence of Sexual Harassment Variables

Level of Harassment

Percent Reported (of those reporting harassment)

Gender Harassment (Level 1)

$68.0 \%$

Seductive Behavior (Level 2)

$45.0 \%$

Sexual Bribery (Level 3)

$5.0 \%$

Sexual Coercion (Level 4)

$4.5 \%$

Sexual Assault (Level 5)

$18.6 \%$

Note: $\underline{N}=$ Of the 118 survey respondents; $85(72 \%)$ reported being sexually harassed. 
Table 2

Pearson Correlation Coefficients for Study Variables

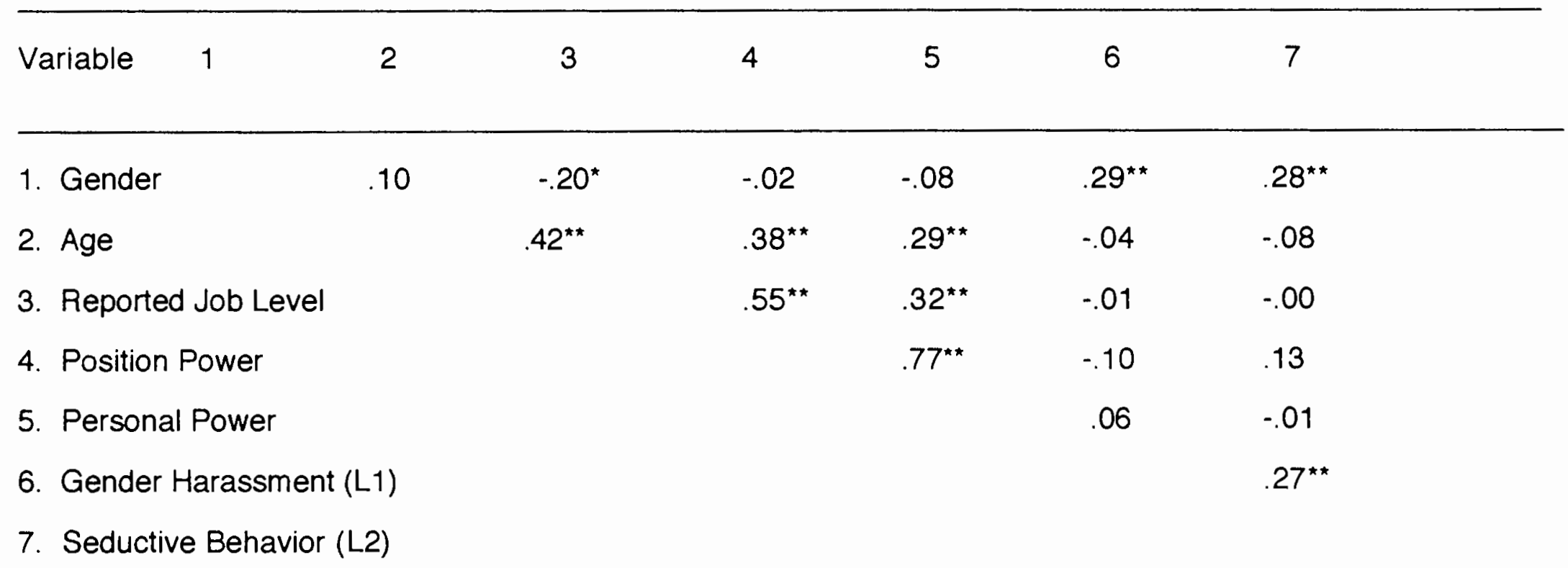

Note: $\underline{N}=118$ survey respondents. ${ }^{*} p \leq .05 ;{ }^{\star *} p \leq .01, L=$ Level. 
Table 3

Responses to the survey question "Sexual Harassment occurs in my workplace."

Likert-type scale response Total percent $\quad$ Male percent $\quad$ Female percent

\begin{tabular}{lccc}
\hline Never & $13.3 \%$ & $11.8 \%$ & $15.2 \%$ \\
Seldom & $52.4 \%$ & $66.6 \%$ & $34.8 \%$ \\
Occasionally & $21.9 \%$ & $16.8 \%$ & $28.3 \%$ \\
Often & $10.5 \%$ & $3.3 \%$ & $19.6 \%$ \\
Almost Always & $1.9 \%$ & $1.5 \%$ & $2.1 \%$ \\
\hline
\end{tabular}

Note: $\underline{N}=118$ survey respondents. 
Table 4

Responses to the survey question "Sexual Harassment is NOT a problem in my workplace."

\begin{tabular}{lccc}
\hline Likert-type scale response & Total percent & Male percent & Female percent \\
\hline Definitely Disagree & $15.2 \%$ & $6.4 \%$ & $26.1 \%$ \\
Somewhat Disagree & $19.0 \%$ & $20.0 \%$ & $17.5 \%$ \\
No Opinion & $10.5 \%$ & $5.0 \%$ & $17.4 \%$ \\
Somewhat Agree & $30.5 \%$ & $40.0 \%$ & $19.5 \%$ \\
Definitely Agree & $24.6 \%$ & $28.6 \%$ & $19.5 \%$ \\
\hline
\end{tabular}

Note: $\underline{N}=118$ survey respondents. 
Table 5

Results of the MANOVA Analysis of Gender and Levels of Power

\begin{tabular}{lcc}
\hline Power Variables & $E$ & Sig. of F \\
\hline Overall Wilks Multivariate Test & 3.22 & .03 \\
Univariate Tests & & .82 \\
$\quad$ Position Power & .05 & .15 \\
Personal Power & 2.06 & .04 \\
Reported Job Level & 4.34 & \\
\hline
\end{tabular}

Note: $\underline{N}=118$ survey respondents. 
Table 6

Results of Multiple Hierarchical Regression Analysis of Power and Incidence of Sexual Harassment

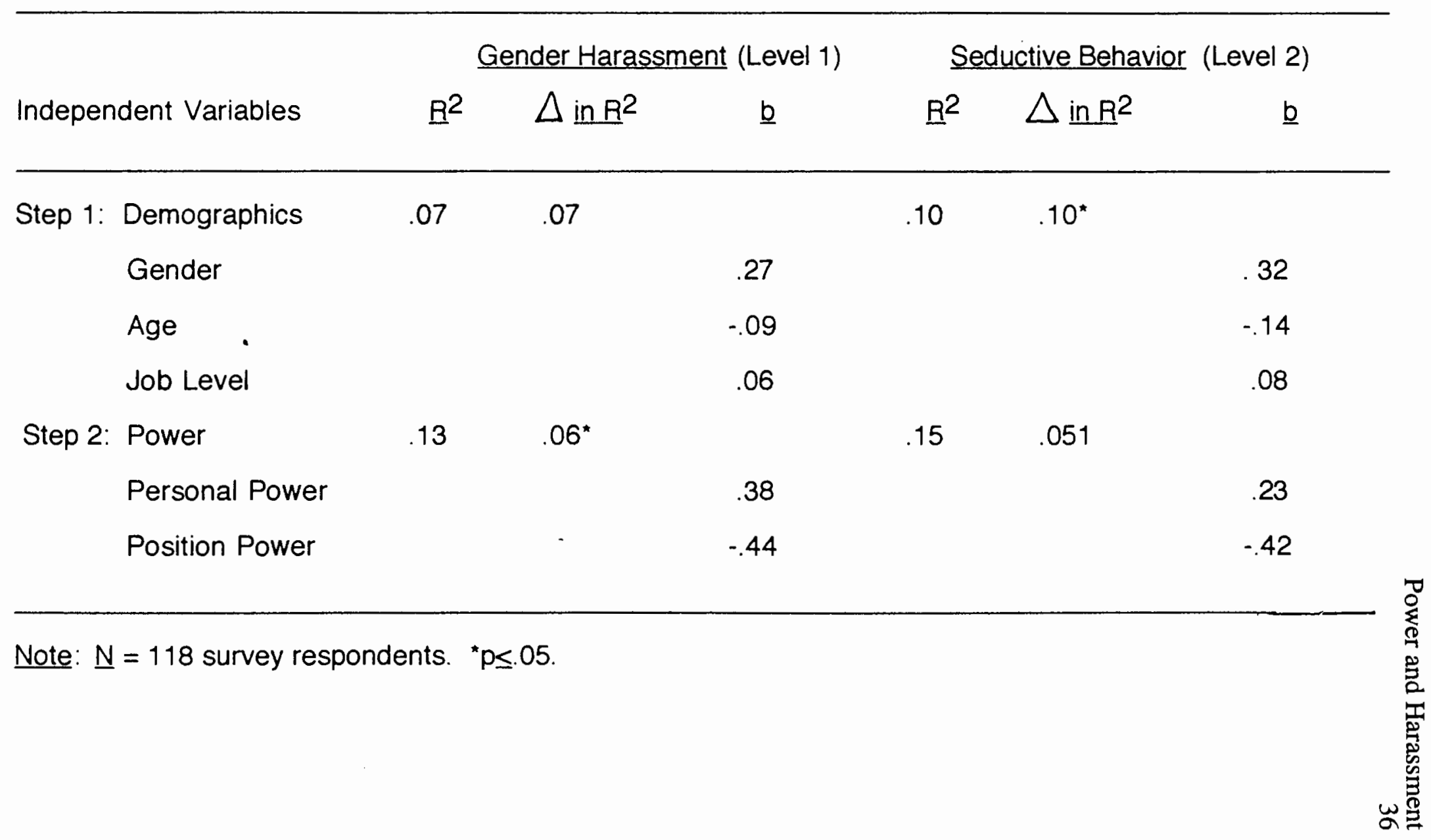


Table 7

Results of Multiple Hierarchical Regression Analysis of Power and Incidence of Witnessing Sexual Harassment

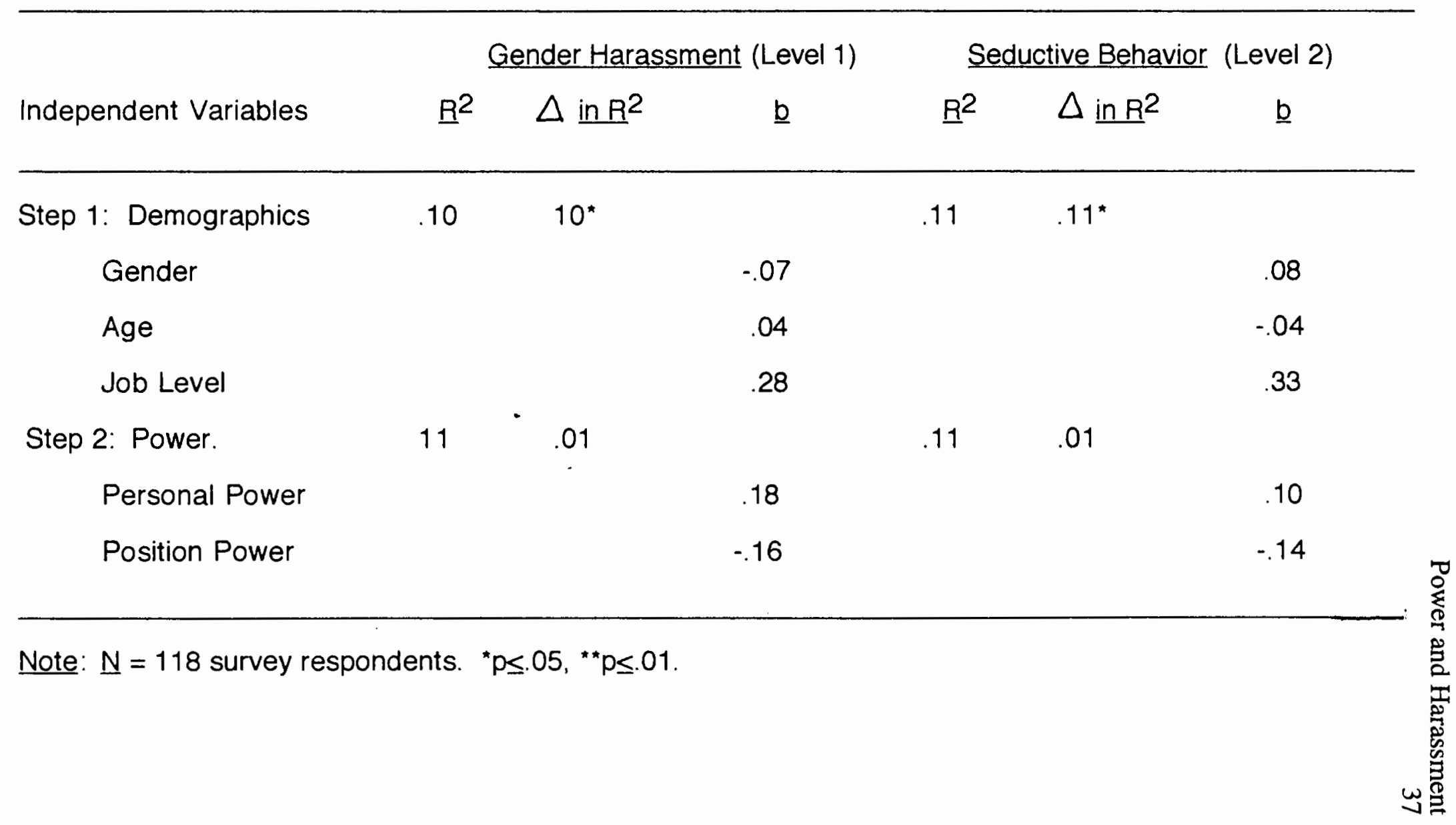


Table 8

Results of Single Regression Analysis of Gender and Sexual Harassment

\begin{tabular}{lcccc}
\hline & \multicolumn{2}{c}{ Gender Harassment (Level 1) } & \multicolumn{2}{c}{ Seductive Behavior (Level 2) } \\
Independent Variables & $\underline{R}^{2}$ & $\underline{F \text { for } R^{2}}$ & $\underline{R^{2}}$ & $\underline{F \text { for R }}$ \\
\hline Gender & .08 & $10.00^{\star *}$ & .08 & $9.38^{\star *}$ \\
\hline
\end{tabular}

Note: $\underline{N}=118$ survey respondents. ${ }^{\star \star} p \leq .01$. 


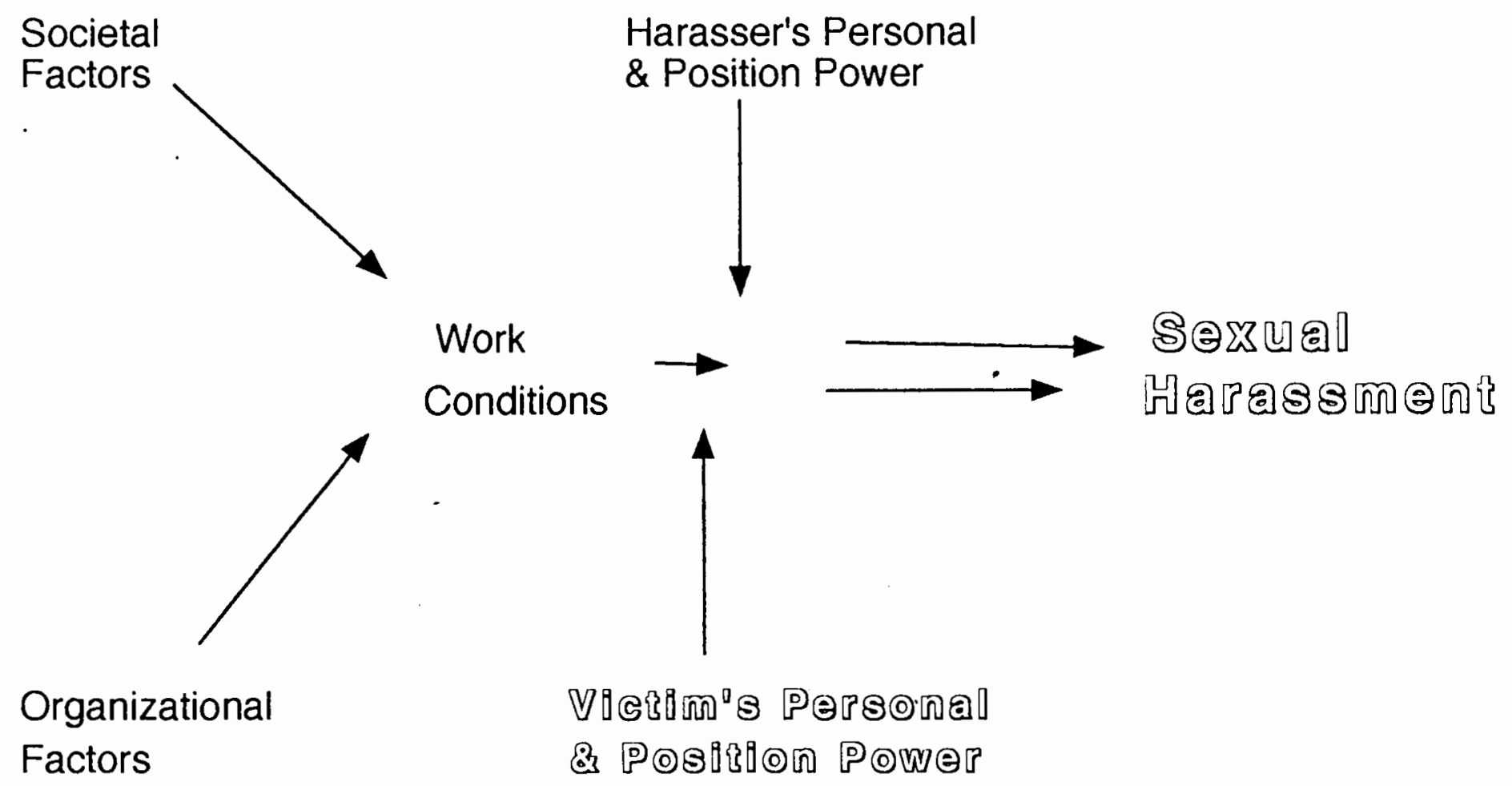

Figure 1. The Cleveland and Kerst model of power and sexual harassment. 


\section{References}

Barak, A., Pitterman, Y. \& Yitzhaki, R. (1995). An Empirical Test of the Role of Power Differential in Originating Sexual Harassment. Basic and Applied Social Psychology, 17(4), 497-517.

Bowes-Sperry, L. \& Powell, G. N. (1996). Sexual Harassment as a Moral Issue: An Ethical Decision-Making Prospective. In M. S. Stockdale, Sexual Harassment in the Workplace, Sage Publications, Inc., Thousand Oaks, CA. Brooks, L. \& Perot, A. R. (1991). Reporting Sexual Harassment:

Exploring a Predictive Model. Psychology of Women Quarterly, 15, $31-47$.

Chapin, B. \& Nortón-Bradley, E. (1993). Sexual Harassment and Gender Sensitivity: Issues for Public Safety Employees. Presented at Washington County Sheriff's Office training.

Cleveland, J. N. \& Kerst, M. E. (1993) Sexual Harassment and Perceptions of Power: An Under-Articulated Relationship. Journal of Vocational Behavior, 42, 49-67.

Cleveland, J. N.. \& McNamera, K. (1996). Understanding Sexual Harassment: Contributions from Research on Domestic Violence and Organizational Change. In M. Stockdale, Sexual Harassment in the Workplace. SAGE Publications, Inc., Thousand Oaks, CA.

Dandekar, N. (1990). Contrasting Consequences: Bringing Charges of Sexual Harassment Compared with Other Cases of Whistle-blowing. Journal of Business Ethics, 9 , 151-158. 
Fitzgerald, L. F. \& Shullman, S. L. (1993) Sexual Harassment:

A Research Analysis and Agenda for the 1990's. Journal of Vocational Behavior, 42, 5-27.

Fitzgerald, L. F., Shullman, S. L., Bailey, N., Richards, M., Swecker, J., Gold, Y., Ormerod, M. \& Weitzman, L. (1988). The Incidence and Dimensions of Sexual Harassment in Academia and the Workplace. Journal of Vocational Behavior, 32 , 152-175.

French, J. \& Raven, B. (1959). The Bases of Social Power. In D. Cartwright (Ed.), Studies in Social Power (pp. 150-167). Ann Arbor, MI; Institute for Social Research.

Frost, D. E. \& Stahalski, A. J. (1988). The Systematic Measurement of French and Raven's Bases of Social Power in Workgroups. Journal of Applied Social Psychology, 18 375-389.

Gruber, J. E. (1989). How Women Handle Sexual Harassment: A Literature Review. Sociology and Social Research, 74, 3-9.

Gruber, J. E. \& Smith, M. D. (1995). Women's Responses to Sexual Harassment: A Multivaniate Analysis. Basic and Applied Social Psychology, 17(4), 543-562.

Gutek, B. A. \& Koss, M. P. (1993). Changed Women and Changed Organizations: Consequences of and Coping with Sexual Harassment. Journal of Vocational Behavior, 42, 28-48. 
Hulin, C. L., Fitzgerald, L. F., \& Drasgow, F. (1996) Organizational Influences on Sexual Harassment. In M. S. Stockdale, Sexual Harassment in the Workplace, Sage Publications, Inc. Thousand Oaks, CA.

Jensen, I. W. \& Gutek, B. A.. (1982). Attributions and Assignments of Responsibility in Sexual Harassment. Joumal of Social Issues, 38(4), 121136.

Kenig, S. \& Ryan, J. (1986) Sex Differences in Levels of Tolerance and Attribution of Blame for Sexual Harassment on a University Campus. Sex Roles, 15, 535-549.

Kerst, M. E. \& Cleveland, J. N. (1993). A Model for Investigating Perceptions of Power and Sexual Harassment: Articulation of Research Needs. Presented at the 1993 Society for Industrial/ Organizational Psychology Conference, San Francisco, CA.

Kipnis, D. (1009). Technology and Power, Springer-Verlag, Inc., New York, NY.

Koss, M. P. (1990). Changed Lives: The Psychological Impact of Sexual Harassment. In M. Paludi, Ivory Power: Sexual Harassment on Campus. SUNY Press, Albany, NY.

Koss, M. P. \& Dinero, T. E. (1988). Predictors of Sexual Aggression Among a National Sample of Male College Students. In R. A. Prentky \& V. L. Quinsey (Eds.) The Annals of The New York Academy of Sciences, 528, 133-147.

Lach, D. H. \& Gwartney-Gibbs, P. A. (1993) Sociological Perspectives on Sexual Harassment and Workplace Dispute 
Resolution. Journal of Vocational Behavior 42 , 102-115.

Near, J. P. \& Meceli, M. P. (1987). Whistle-blowers in Organizations:

Dissidents or Reformers? Research in Organizational Behavior $\underline{9}, 321-368$.

Pfeffer, J. (1981). Power in Organizations. Boston, MA, Pitman.

Pfeffer, J. (1992). Managing with Power. Harvard Business School Press, Boston, MA.

Powell, G. N. (1993). Women and Men in Management. SAGE, Newberry Park, CA.

Pryor, J. B. (1987). Sexual Harassment Proclivities in Men. Sex Roles, 17, 269-290.

Pryor, J. B., LaVille, C. M. \& Stoller, L. M. (1993). A Social Psychological Analysis of Sexual Harassment: The Person/Situation Interaction. Journal of Vocational Behavior $\underline{42}$, 68-83.

Ragins, B. R., \& Sundstrom, E. (1989). Gender and Power in Organizations: A Longitudinal Perspective. Psychological Bulletin, 105, 5188.

Raven, B:H. (1983). Interpersonal Influence and Social Power. In B. H.. Raven \& J. Z. Rubin, Social Psychology, New York: $399-438$.

Stockdale, M. S. (1996). Sexual Harassment in the Workplace. SAGE

Publications, Inc., Thousand Oaks, CA.

Stockdale, M. S., Vaux, A. (1995). What Sexual Harassment Experiences Lead Respondents to Acknowledge being Sexually Harassed? 
A Secondary Analysis of a University Study. Journal of Vocational Behavior, 43, 221-224.

Stockdale, M. S. (1993). The Role of Sexual Misperceptions of Women's Friendliness in an Emerging Theory of Sexual Harassment. Journal of Vocational Behavior, 42, 84-101.

Thacker, R. A. (1996). A Descriptive Study of Situational and Individual Influences upon Individuals' Responses to Sexual Harassment. Human Relations, 49(8), 1105-1122.

U.S. Merit System Protection Board (1988). Sexual Harassment in the Federal Government: An Update. Washington D.C. Office of Merit System Review and Studies, Government Printing Office.

Yukl, G. A. (1989) Leadership in Organizations. Prentice-Hall Inc. Publishing, Englewood Cliffs, NJ. 
Appendix

Questionnaire

May 22, 1995

To all respondents:

The enclosed survey is being conducted by a Portland State University Master's Degree student to fulfill the Thesis requirement. Your participation in this project is completely voluntary and your assistance would be appreciated.

County Administrator Charlie Cameron has agreed to allow you to complete the questionnaire on your work time; you do not need to stay after your shift in order to participate. However, it is also acceptable to answer the questions at home and bring it back to work. It will take approximately 10 minutes to complete the questionnaire.

The survey is totally anonymous . This means that it is not marked in any way for identification purposes, and no one will be able to match you to your answers on this form. To ensure complete anonymity, a return envelope is also enclosed. If you choose to finish the survey, just place it in the return envelope, seal it, and put it in the drop box marked "Questionnaire Drop Box" located in Records and near the elevator on the first floor of the jail.

Once the questionnaires are analyzed, the overall results will be presented to the County administrators in order to assist them in the development of any training that may help Washington County employees.

Please complete the survey by June 5 and drop it in one of the designated secure boxes. If you have any problems or questions, please contact Dr. Leslie Hammer at Portland State University at 725-3971, or the Portland State Human Subjects Research Review Committee. Your participation is greatly appreciated!

If you have concerns or questions about this study, please contact the Chair of the Human Subjects Research Review Committee, Office of Research and Sponsored Projects, 105 Neuberger Hall, Portland State University, (503) 725-3417. 
Please read each statement carefully, and then circle the appropriate number indicating your use of that behavior with other people in the workplace. Remember that you are rating how you actually behave with your co-workers, not what you think is desirable or should be done.

$\begin{array}{ccccc}1 & 2 & 3 & 4 & 5 \\ \text { Never } & \text { Seldom } & \text { Occasionally } & \text { Often } & \text { Almost Always }\end{array}$

\section{POSITION POWER}

Promote others or recommend

them for promotion.

Demote them or recommend them

for demotion.

$\begin{array}{lllll}1 & 2 & 3 & 4 & 5\end{array}$

Expect that your orders and requests will be carried out because you are the boss and they will not question an order from you.

Persuade others by using relevant facts.

$\begin{array}{lllll}1 & 2 & 3 & 4 & 5\end{array}$

Recommend others for awards or for announcements of recognition.

$\begin{array}{lllll}1 & 2 & 3 & 4 & 5\end{array}$

Make on-the spot corrections

$\begin{array}{lllll}1 & 2 & 3 & 4 & 5\end{array}$

$\begin{array}{lllll}1 & 2 & 3 & 4 & 5\end{array}$

Let others know that you have a right to expect that your directions will be followed

$\begin{array}{lllll}1 & 2 & 3 & 4 & 5\end{array}$

Give others high performance ratings

$\begin{array}{lllll}1 & 2 & 3 & 4 & 5\end{array}$

Give others low performance ratings

$\begin{array}{lllll}1 & 2 & 3 & 4 & 5\end{array}$

Give others interesting, challenging assignments

$\begin{array}{lllll}1 & 2 & 3 & 4 & 5\end{array}$

Emphasize that you probably have information that they do not have, and that is a good reason to complete any direct request or order

Give others information they lack $\begin{array}{lllll}1 & 2 & 3 & 4 & 5\end{array}$

Give others boring, routine assignments

$\begin{array}{lllll}1 & 2 & 3 & 4 & 5\end{array}$

$\begin{array}{lllll}1 & 2 & 3 & 4 & 5\end{array}$ 
$\begin{array}{ccccc}1 & 2 & 3 & 4 & 5 \\ \text { Never } & \text { Seldom } & \text { Oocasionally } & \text { Often } & \text { Almost Always }\end{array}$

Give others useful information to improve

their job performance

$\begin{array}{lllll}1 & 2 & 3 & 4 & 5\end{array}$

Give others extra time off as a reward

$\begin{array}{lllll}1 & 2 & 3 & 4 & 5\end{array}$

Give others extra work as punishment

$\begin{array}{lllll}1 & 2 & 3 & 4 & 5\end{array}$

Recommend others for formal disciplinary

action or reprimands

$\begin{array}{lllll}1 & 2 & 3 & 4 & 5\end{array}$

Provide others with information so that

they will take action

$\begin{array}{lllll}1 & 2 & 3 & 4 & 5\end{array}$

Control what kind and/or how much

information is passed on to others

$\begin{array}{lllll}1 & 2 & 3 & 4 & 5\end{array}$

\section{PERSONAL POWER}

Advise and assist others.

$\begin{array}{lllll}1 & 2 & 3 & 4 & 5\end{array}$

Set the example and rely upon others to follow my example.

$\begin{array}{lllll}1 & 2 & 3 & 4 & 5\end{array}$

Use your good relationship with them

to get the job done

$\begin{array}{lllll}1 & 2 & 3 & 4 & 5\end{array}$

Explain the reasons why the request

will result in a desired outcome

$\begin{array}{lllll}1 & 2 & 3 & 4 & 5\end{array}$

Rely upon other people to get the job done because they don't want to let you down

Praise others

$\begin{array}{lllll}1 & 2 & 3 & 4 & 5\end{array}$

Criticize others

$\begin{array}{lllll}1 & 2 & 3 & 4 & 5\end{array}$

$\begin{array}{lllll}1 & 2 & 3 & 4 & 5\end{array}$

Count on others to believe that it is to their advantage as much as it is to yours

for them to cooperate with you

$\begin{array}{lllll}1 & 2 & 3 & 4 & 5\end{array}$

Get others to accomplish the work by

demonstrating that you know how to

perform the task

$\begin{array}{lllll}1 & 2 & 3 & 4 & 5\end{array}$

Impress others with your overall

competence and ability

$\begin{array}{lllll}1 & 2 & 3 & 4 & 5\end{array}$ 
Read each item carefully, and place an " $\mathrm{X}$ " in the first column if the incidents listed happened to you while working at Washington County, and/or an " $X$ " in the second column if you have been $a$ direct witness to the incident while at work at Washington County, You can mark both columns on one question if both choices apply.

\section{GENDER HARASSMENT}

Has applied

Others telling suggestive stories or offensive jokes

Others making crude sexual remarks

Seductive remarks

Staring or leering

Display , use or distribute sexual material or pornography

Treated differently due to gender

Sexist remarks about women's behavior or career options

\section{SEDUCTIVE BEHAVIOR}

Unwanted discussion of personal or sexual material

Unwelcome sexual behavior

Unwelcome sexual attention

Unwelcome seductive behavior

Unwanted propositions

Invasion of privacy (i.e., repeated calling, "dropping by", etc.)

Sexual insinuation or innuendo

Crude or offensive sexual remarks made to others about you or co-workers

Sexual rumors spread about you or co-workers

\section{SEXUAL BRIBERY}

Subtle bribery for sexual cooperation to you

Witnessed at work
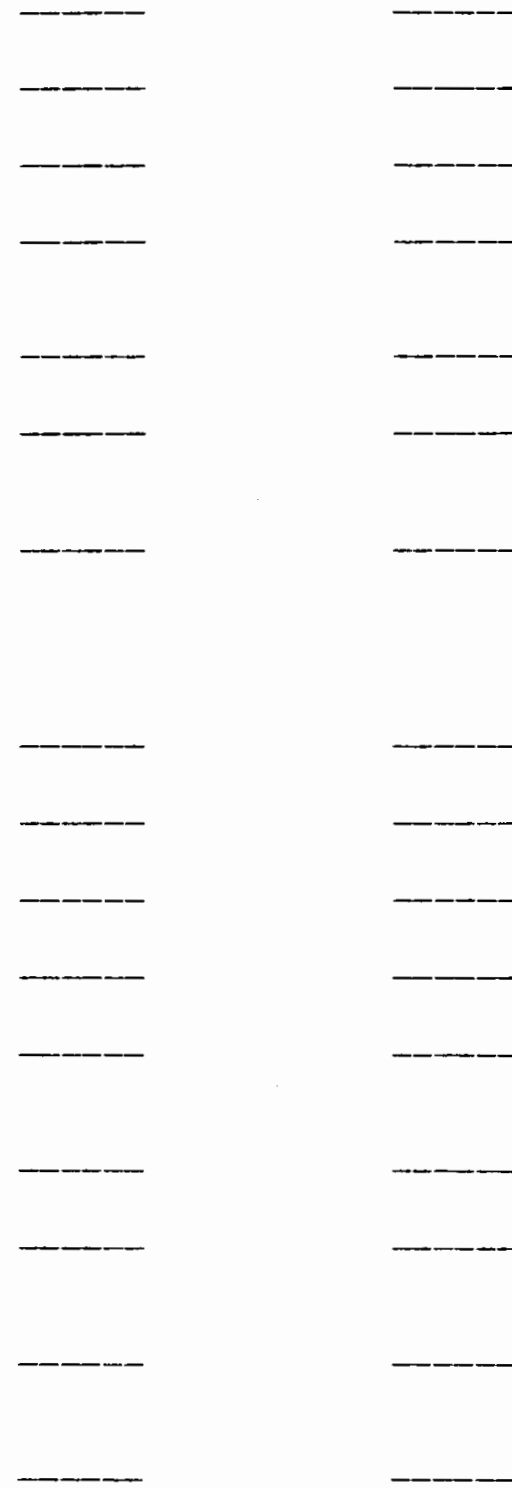
Has applied

to you

Direct bribery

Engaged in unwanted sexual behavior due to promise of reward

Actually rewarded for sexual cooperation

\section{SEXUAL COERCION}

Subtle threats of retaliation for noncooperation of sexual acts

Direct threats related to sexual acts

Engaged in unwanted sexual behavior due to threat of retaliation

Actually experienced negative consequences for sexual non-cooperation

\section{SEXUAL ASSAULT}

Deliberate touching

Unwanted attempts to touch you or co-workers sexually

Forceful attempts to touch you or co-worker sexually

Indecent exposure

Attempts at intercourse that resulted in your or a co-worker crying, pleading or physically struggling

Attempts to touch genitals

Forceful attempts at intercourse
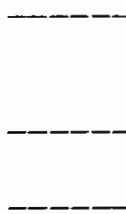

Witnessed

at work

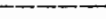

. 
Please read each statement carefully, and then circle the appropriate number which corresponds to your opinion.

Sexual harassment occurs in my workplace.

$\begin{array}{ccccc}1 & 2 & 3 & 4 & 5 \\ \text { Never } & \text { Seldom } & \text { Occasionally } & \text { Often } & \text { Almost Always }\end{array}$

Sexual harassment is net a problem in my workplace.

$\begin{array}{ccccc}1 & 2 & 3 & 4 & 5 \\ \text { Definitely } & \text { Somewhat } & \text { No } & \text { Somewhat } & \text { Definitely } \\ \text { Disagree } & \text { Disagree } & \text { Opinion } & \text { Agree } & \text { Agree }\end{array}$

Washington County needs to pay more attention to preventing sexual harassment among its employees.

$\begin{array}{ccccc}1 & 2 & 3 & 4 & 5 \\ \text { Definitely } & \text { Somewhat } & \text { No } & \text { Somewhat } & \text { Definitely } \\ \text { Disagree } & \text { Disagree } & \text { Opinion } & \text { Agree } & \text { Agre⿻ }\end{array}$

Washington County should not spend money in an attempt to educate its employees about sexual harassment.

$\begin{array}{ccccc}1 & 2 & 3 & 4 & 5 \\ \text { Definitely } & \text { Somewhat } & \text { No } & \text { Somewhat } & \text { Definitely } \\ \text { Disagree } & \text { Disagree } & \text { Opinion } & \text { Agree } & \text { Agree }\end{array}$

Job Level

Non-supervisory

Supervisor

Supervise others who are also supervisors

Number of Years employed at Washington County:

Age:

\section{Ethnicity}

White, non-Hispanic Hispanic African American

Asian or Pacific Islander Native American Other 